\title{
IVIG sind sicher, aber die Infusion ist alle zwei Wochen notwendig
}

Fragestellung: Kleinere Studien legten nahe, dass intravenöse Immunglobuline (IVIG) Biomarker und Symptome bei der Alzheimer-Demenz (AD) beeinflussen. Diese Studie untersuchte Sicherheit, Dosisfindung und das optimale Infusionsintervall.

Hintergrund: Im Serum gibt es Antikörper gegen Amyloid $\beta$ $(\mathrm{A} \beta)$, die bei Patienten mit AD reduziert sind. Drei Studien haben bisher die Wirksamkeit von den bei anderen neurolo-

Dodel $R$, Rominger A, Bartenstein $P$ et al. Intravenous immunoglobulin for treatment of mild-to-moderate Alzheimer's disease: a phase 2, randomised, double-blind, placebo-controlled, dose-finding trial. Lancet Neurol 2013; 12: 233-43 gischen Krankheiten wirksamen und zugelassenen IVIGbei der AD untersucht. Unklar blieben dabei die effektive Dosis und das Intervall.

Patienten und Methodik: Phase-II-Studie über 22 Wo- chen an 89 Patienten ( 50 bis 85 Jahre) mit leichter bis moderater $A D$ in zwölf Zentren (sieben in den USA, fünf in Deutschland). Die Randomisierung erfolgte $1: 1$ zu entweder 0,2 oder 0,5 oder $0,8 \mathrm{~g} / \mathrm{kg}$ IVIG versus Placebo alle vier Wochen oder zu 0,1, 0,25, oder $0,4 \mathrm{~g} / \mathrm{kg}$ IVIG versus Placebo alle zwei Wochen.

Ergebnisse: Insgesamt konnten die Daten von 55 Patienten ausgewertet werden. Das mittlere Integral des Plasma-A $\beta$ zwischen IVIG und Placebo unterschied sich für fünf von sechs Gruppen nicht signifikant. Nur die Gruppe 0,4 g/kg IVIG alle zwei Wochen war signifikant. Die Rate leichter Nebenwirkungen war nicht unterschiedlich, schwere Nebenwirkungen traten in der Placebogruppe häufiger auf.

Schlussfolgerungen: IVIG haben ein akzeptierbares Sicherheitsprofil bei der AD, müssen aber in längeren Studien untersucht werden.

\section{- Kommentar von Markus Weih, Nürnberg}

\section{IVIG bleiben eine interessante Option}

Endlich liegt eine ausreichend große und qualitativ hochwertige Studien zu Immunglobulinen (IVIG) bei der AlzheimerDemenz vor. Besonders erfreulich ist, dass die Studie in großen Teilen in Deutschland durchgeführt wurde. Wie auch für andere Anwendungen zeigte sich eine gute Verträglichkeit der IVIG. In dem kurzen Beobachtungszeitraum zeigte sich außer für die Hochdosisgruppe kein Effekt auf den A $\beta$-Plasmaspiegel, ein Effekt der sich paradoxerweise in kleineren Studien schon gezeigt hatte. Natürlich kann man daraus noch nicht auf einen negativen Therapieeffekt schließen. Allerdings gab es in der Verumgruppe auch einen erhöhten Glukoseumsatz im FDGPET frontal, einer Region, die eigentlich im leichten bis mittleren Krankheitsstadium noch nicht so betroffen ist. Durch die sechs Behandlungsarme sind die Subgruppen leider sehr klein geworden, sodass es insgesamt sehr schwierig ist, Schlussfolgerungen aus der Studie zu ziehen. Angesichts der Tatsache,

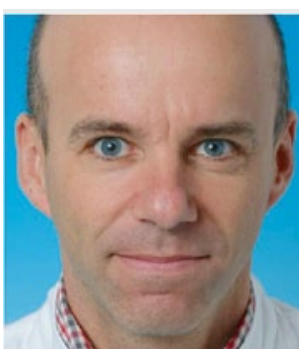

Prof. Dr. med. Markus Weih, Nürnberg

Facharzt für Neurologie,

Psychiatrie und Psychotherapie

Nervenärztliche Gemeinschaftspraxis,

Nürnberg

E-Mail:weih@nervenaerzte-

allersbergerstrasse.de dass in den Tiermodellen erfolgreiche Strategien in den letzten Jahren bei der AD sämtlich scheiterten, die aktive Immunisierung technisch schwierig ist und die bewährten Cholinesterasehemmer nur begrenzt wirksam sind, sollten passive Anti-A $\beta$-Immunstrategien bei der AD weiterverfolgt werden. Ob AD-Patienten irgendwann einmal tatsächlich jahrelang alle zwei Wochen für eine teure Infusion in die Praxis kommen, ist natürlich völlig offen. Als Proof-of-principle im Rahmen von Studien bleiben IVIG jedoch eine interessante Option.

Anzeige

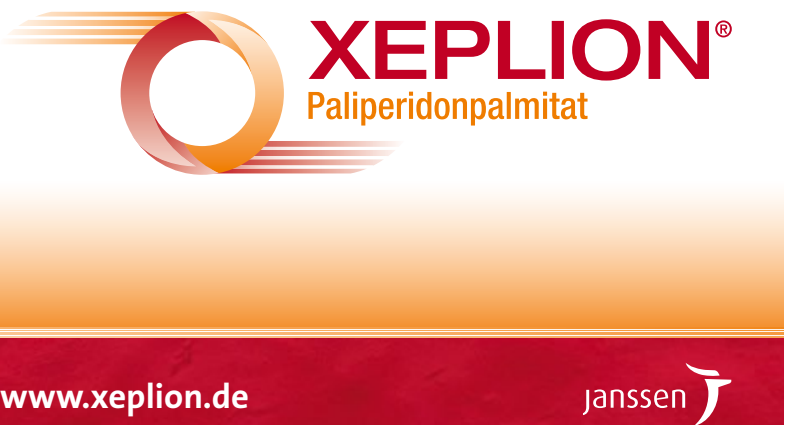

